\title{
¿Crisis del hispanismo? Visiones contra-canónicas y discursos críticos
}

\author{
Jean-François Botrel \& Maria Vittoria CALVI ${ }^{\mathrm{I}}$ \\ Université de Rennes \& Università degli Studi di Milano
}

\begin{abstract}
Desde su asentamiento como disciplina académica se ha venido cuestionando el frágil estatuto epistemológico del hispanismo. A partir de los años 1980, se intensificaron las críticas a un hispanismo académico volcado hacia España, estricta o mayoritariamente filológico y clásico, que abrieron paso a visiones contra-canónicas. Con la mirada puesta en este proceso, pero sin desestimar la pujante vitalidad del hispanismo, en el presente artículo se analizan los efectos sobre la disciplina de la crisis de las humanidades y de la globalización. Sin pretensión a establecer un «nuevo paradigma», se contempla la necesidad, para el hispanismo, de tomar conciencia del peligro de una desconexión entre la tradición universitaria y las expectativas de la sociedad. Se aboga por un hispanismo comprometido con su momento histórico y su función crítica ; un hispanismo no hegemónico ni unívoco, sino abierto y plural y, al mismo tiempo, crítico y combativo.
\end{abstract}

Keywords: hispanismo, hispanista, estudios hispánicos, crisis humanidades; globalización, lengua española, hispanoproclividad, estudios areales.

\section{¿Crisis del hispanismo?}

Puede parecer extraña -incluso incongruente- tal pregunta, cuando el español en el mundo, en sus distintas modalidades, está gozando de buena y hasta excelente salud, con el crecimiento del número de hispanohablantes en su espacio histórico y fuera (un I8\% de hispanohablantes en los Estados Unidos de América: 57, 5 millones), con el auge de la enseñanza del español en el sistema de formación secundaria y superior de los cinco continentes (cfr. el caso espectacular de Brasil donde hasta 2016 el español fue lengua obligatoria en la enseñanza media) y el consiguiente aumento del número de profesores de español e hispanistas potenciales. Un proceso expansivo que ha aumentado enormemente el ámbito de la hispanoproclividad -para emplear la nueva categoría semántica propuesta por Ángel López García (20I4) - es decir, el conjunto de las personas que lo hablan como lengua ex-

I Jean-François Botrel (Universidad de Rennes 2, Francia. Presidente de Honor AIH), Presidente de mesa \& Maria Vittoria Calvi (Università degli Studi di Milano). Con la colaboración de Pedro Álvarez de Miranda (Académico de la RAE. Universidad Autónoma de Madrid); Fausta Antonucci (Universidad Roma Tre, Italia); Maria Augusta da Costa Vieira (Universidad de São Paulo, Brasil); Eugénie Eyeang (Gabón); Abeer Mohamed Abdel Salam Zahana (Universidad de El Cairo, Egipto); Jelena Spasojević (Presidenta de la Asociación de Hispanistas de Serbia). 
tranjera o segunda, por razones no meramente prácticas, sino por los valores interculturales que encierra, ante otras lenguas occidentales (López García 20I0).

Sea lo que fuere, siquiera como hipótesis de escuela, la existencia de una posible crisis de crecimiento, de identidad, etc., del hispanismo es un saludable suponer por la dimensión epistemológica que conlleva y la reflexión - casi podríamos decir el examen de conciencia- a que obliga por parte de cualquier hispanista amigo de pensar su propio ser y quehacer y la historia ya secular del hispanismo.

Unos cuestionamientos consustanciales del hispanismo. Este cuestionamiento viene de muy atrás -podríamos decir que coincide con los principios del hispanismo- y, entre los hispanistas, es como constitutivo y consustancial de una neo-disciplina de unos aún imprecisos contornos el hispanismo científico vs la hispanofilia en tiempos de Morel-Fatio y Menéndez y Pelayo, la diferencia entre hispanistas hispanólogos y los hispanistas hispanófilos, según Rafael Altamira (apud Botrel 20I4), el hispanismo no únicamente de templa serena por el que, en I920, abogaba Menéndez Pidal o sea no de pura erudición sino «más vivo, más amplio, más directo» y que aunara los aspectos literario, lingüístico y utilitario -así lo decía (Botrel 20I4) - o un hispanismo que se interesara por el trasfondo popular de una «authentic Spain» reivindicado por algunos filólogos o folkloristas como Aurelio M. Espinosa, Krüger, Kmemme, Schindler en el Entreguerras, la hispanística en su proceso de independización de la romanística (en Alemania no sucede hasta los años I980) y su coexistencia, desde el punto de vista geográfico/areal, hasta hoy, con el americanismo o el hispanoamericanismo ${ }^{2}$. Observemos que, si bien el hispanismo científico se fue constituyendo a partir de la filología (lengua y literaturas) y de la historia, al principio, la afición de los hispanistas «al estudio de la lengua y la literatura españolas y de las cosas de España», como decía el diccionario de la Real Academia Española, o «al estudio de las lenguas, literaturas o cultura [sin plural] hispánicas» como dijo después, pudo ser mucho más amplio3, y que el propio término "hispanismo" no ha llegado a ser totalmente unívoco: además de significar un barbarismo en otros idiomas, hispanismo es todavía sinónimo de una sensibilidad peculiar en el campo de la creación ${ }^{4}$ y, a partir de los años I920, bajo el primer

\footnotetext{
2 El primer congreso de la Société Américaine se celebró en Nancy (Francia) en I875. En 2018, en el $56^{\circ}$ Congreso internacional de americanistas, celebrado en Salamanca, caben todas las disciplinas (cfr. http://ica2or8.es).

3 Se calcula, por ejemplo, que un I6 \% de las tesis de tema hispánico leídas en Francia hasta I980 versaban sobre medicina y un $48 \%$ sobre derecho o ciencias económicas (cfr. Guittard 1993).

4 Cfr. por ejemplo, los textos dedicados a Camões y su hispanismo (Viqueira 1972) o al hispanismo de los sefardíes levantinos (Bernardete 1963) o «el hispanismo y el italianismo musical en la época de la tonadilla», según José Subirá (1924).
} 
franquismo y aún hasta hoy, se ha entendido como proyecto ideológico y voluntad de proyección propios de España: de ahí la asociación entre nacionalismo e hispanismo por Andrenio, los discursos de Martín Artajo como motivo del Día o Fiesta de la hispanidad entre 1947 y $1955^{5}$, la fundación por iniciativa del Ministerio español de Asuntos Exteriores de una Asociación del Hispanismo Internacional, con su revista Clavileño (Mainer 2002) hasta hoy, en la web, donde «hispanismo.org» está dedicado «a los hechos pasados y presentes desde una óptica hispanista». Algún proyecto muy científico se propone "analizar el hispanismo» de algunas colecciones conservadas en las bibliotecas de Ginebra, etc.

Lo cierto es que el hispanismo en su acepción y vertiente académica -la que se va a contemplar aquí ${ }^{6}-$ ha tardado bastante $\mathrm{I}^{\circ}$ en percibirse como algo específico entre los profesores de las lenguas modernas y luego románicas (o "meridionales") e incluso ibéricas, y en conquistar su autonomía en el ámbito de la filología románica o de la romanística ; $2^{\circ}$ en aplicarse a unos "nuevos" espacios como Hispanoamérica o la América del Norte hispanófona, con los llamados estudios areales cuyos límites, por la historia o la geoestrategia, pueden variar según desde dónde se mire (la americanidad englobadora o disgregada, la latinidad $v s$ el mundo anglosajón, el multilinguismo dentro de la misma nación, la visión europea de España e Hispanoamérica, etc.) (Botrel 2019) ; y $3^{\circ}$, en general, en hacerse reconocer como disciplina cabal ya que todavía le cuesta imponerse como una corriente aglutinadora de intereses con amplia base socio-cultural ${ }^{7}$.

También se puede observar que el hispanismo y los hispanistas, de alguna manera, siempre han manifestado, con mayor o menor intensidad y de manera más o menos explícita, unas preocupaciones actuales, o sea contemporáneas o de permanente actualidad. Muy sabido es que, en muchos países -caso de Inglaterra, Francia e Italia-, lo que después se llamaría hispanismo nació con la enseñanza de la lengua con finalidades económicas o

5 Dedicados a «la hispanidad», «la gran familia hispánica», «la comunidad hispánica», «la supranacionalidad hispánica», y, una vez, a «los pueblos hispánicos».

6 Tampoco podemos olvidar, sin embargo, que desde el mundo académico, el hispanismo entendido como ideología ha sido sometido a un proceso crítico, que tiene su fundamento teórico en las orientaciones más "heterodoxas" de la sociolingüística actual, del análisis del discurso y de la glotopolítica (véanse, por ejemplo, del Valle \& Gabriel-Stheeman 2004, del Valle 20I2).

7 Una encuesta sociolingüística tipo «¿Qué quiere decir hispanismo e hispanista?» en la misma España, no digamos en Hispanoamérica y en los países no hispanófonos seguro que nos depararía muchas sorpresas, no todas muy gratas. En las 330 ocurrencias de "hispanismo" en los descriptores o palabras claves utilizados por la Biblioteca Nacional de España (consulta de I4.6.2018), se observará que la casi totalidad remiten a la palabra existente en el título de la obra o a la denominación de una editorial, y sólo excepcionalmente sirve para calificar una obra, como Vida y obra de Concha Espina de Gérard Lavergne o Spain, an historical enigma de Claudio Sánchez Albornoz (1975). 
geopolíticas, al margen de un interés meramente intelectual o sentimental; algo que aún se puede notar en los hispanismos emergentes (Eyang 1997), o en ciertas políticas estatales reductoras con respecto a la enseñanza del español y de los idiomas en general. Pudo desembocar en algún aggiornamento, como en el caso de la Associazione Ispanisti Italiani (AISPI), preocupada por los aspectos didácticos del hispanismo y acogedora de los profesores de enseñanza secundaria, por lo menos hasta la creación, en 1992, de una asociación específica, AISPIScuola ${ }^{8}$.

El hispanismo se ha constituido dialogando con muchas disciplinas no digamos métodos- desde unas perspectivas casi siempre comparatistas puesto que el hispanismo remite a una consustancial alteridad u otredad y no se trata de una disciplina excluyente sino abarcadora y aglutinadora más que integradora: a ningún hispanista se le ocurriría negar la necesidad de pensar el judeo-español, el catalán, el gallego, las huellas árabes, el español en África, las distintas lenguas amerindias, y todo lo que se les puede asociar como algo al mismo tiempo específico y parte de una historia común no acabada9.

Querer poner límites al hispanismo o introducir fronteras dentro del hispanismo es, pues, como querer poner puertas al campo, incluso hispánico.

Sin ser un cajón de sastre, el hispanismo de hecho, tal y como se desenvuelve y practica es, pues, una casa muy acogedora de intereses o apetencias muy variopintos solo "unificados" por la referencia a un espacio lingüístico y geográfico común, a un área. Estaríamos por decir que es una disciplina "polinómica" como lo son determinados idiomas (el corso, p. ej.) o sea una disciplina de disciplinas cuya unidad es abstracta y resulta de un movimiento dialéctico y no de la simple osificación de una norma única y cuya existencia estriba en la decisión masiva de los que la practican de atribuirle un nombre peculiar y de declararla autónoma con respecto a las demás disciplinas $^{10}$.

No todos los que cultivan los estudios relacionados con dicho espacio lingüístico y geográfico se consideran a pleno título hispanistas, debido también a las categorizaciones académicas. La política académica, por otra parte, varía de un país a otro; el hispanismo inglés o el francés, por ejemplo, incluyen a pleno título los estudios históricos y los dedicados a las artes visuales, mientras que en otros países abarca solo la lengua y la literatura.

8 Recuérdese que, a nivel nacional e internacional, existen, para la enseñanza media, varias asociaciones nacionales de profesores de español. La Asociación Europea de Profesores de Español fue fundada en 1968.

9 Para comprobarlo, véase, por ejemplo, el programa del XX Congreso de la Asociación Internacional de Hispanistas (AIH) que se celebró en Jerusalén, en julio de 2019.

Io De ahí, tal vez, la pregunta de Marta López Suaces: «¿Qué queremos decir cuando decimos hispanismo?» (2003). 
Pero, el hispanismo, a pesar de ser, pues, una conjunción y amalgama de unas miradas entrecruzadas de múltiples enfoques, en su vertiente "oficial" o "institucional" (el hispanismo académico y de investigación) queda más centrado en la literatura y en la lengua y subsidiariamente en la cultura (la de la España española clásica y contemporánea, las hispanoamericanas), y menos en la historia que no sea la literaria y casi nada en los demás aspectos del quehacer hispánico.

Conviene tenerlo en cuenta, para procurar entender e interpretar la reciente corriente cuestionadora del hispanismo académico.

\section{El hispanismo a debate desde los años 1980}

Tras la relativa estabilización e institucionalización de lo que significa el hispanismo científico o académico, se ha dado, a finales del siglo xx, una corriente cuestionadora más o menos intensa y caudalosa según los países o desde donde se mire, $y$, en los últimos años, se ha venido hablando de un «nuevo hispanismo»-o, mejor dicho, de «nuevos hispanismos», en plural, como consecuencia del proceso de renovación que ha interesado tanto a los estudios literarios (Ortega 20I0) como a la lingüística hispánica (Zimmermann 20IO), en una perspectiva transatlántica e interdisciplinar.

Dentro de la misma concepción abierta del hispanismo ofrecida por la Asociación Internacional de Hispanistas en el artículo $3^{\circ}$ de sus estatutos ${ }^{\mathrm{II}}$, desde los años I980 se viene observando una creciente diversificación de las miradas: nacionales, disciplinarias (el hispanismo filosófico), metodológicas (semiótica e hispanismo en 1983), temáticas, geográficas (Cataluña, Galicia, Perú, etc.), con incluso la emergencia de un hispanismo español, argentino ${ }^{12}$, mexicano, “atino". Unas tendencias "centrífugas" y "restringidas", con pretensión a la diferenciación y autonomización, unos cotos que sus propios topógrafos saben que no pueden ser cotos cerrados, sino que siempre se trata de unos espacios de encuentro e intercambio. Esta corriente corre pareja con una pertinaz voluntad por cuestionar algo no tan uniforme ni unívoco a nivel internacional, pero que se tiene por hispanismo de referencia, dominante e incluso hegemónico, emisor y guardián al mismo tiempo de una supuesta doxa hispanista de cuño fundamentalmente filológico, clásico y español.

II Según este art. $3^{\circ}$, los fines de la AIH son: «el fomento de los estudios hispánicos en todos los países y el estudio de asuntos de interés común referentes a las lenguas y las literaturas peninsulares e iberoamericanas y de los aspectos culturales relacionados con ellas».

I2 En Argentina, según Raquel Macciuci (2006), hispanismo debe entenderse en el sentido restringido de literatura española y la crítica que se ocupa de ella. 
Esta corriente consistió primero, a principios de los años 1980, en afirmar lo nuevo con respecto a lo antiguo ${ }^{13}$.

Luego, a principios de este siglo, a raíz de lo acuñado como «crisis del hispanismo», muy especialmente a través del dossier sobre el hispanismo publicado en 1995 por Quimera (I39), y de «Hispanismo a debate» en la revista Lateral (diez contribuciones en 2002-2004) y sus prolongaciones (Subirats 2004, Epps \& Cifuentes 2005, Moraña 2005, Resina 2009), se empezó -en los Estados Unidos de América, sobre todo- a cuestionar el hispanismo académico. Un hispanismo que, según sus detractores, se ha constituido como un hispanismo filológico conservador (se denuncia su «anticuarismo») y positivista (cfr. el «agudo positivismo de tantos profesores», señalado por Germán Gullón 2002: 6), a pesar de tantas corrientes intelectuales novedosas, con una «sacralización de los maestros» (Durán 2003) o la reproducción a través del tinglado institucional de las esferas de poder, en detrimento de las nuevas generaciones. Un hispanismo centrado en la lengua española (cuando en muchos países hispanófonos se da un plurilingüismo) y en la literatura en español, cuando convendría «recuperar tradiciones y expresiones artísticas y culturales marginadas y reprimidas». Un hispanismo excluyente que no integrador (Epps 2003), que «suprime las diferencias respecto a la otredad interna y transatlántica» ${ }^{14}$, con la consiguiente reivindicación de otro hispanismo que haga de la disciplina el lugar de encuentro para la coexistencia abierta, plural y equitativa de las diferentes culturas que se desarrollan y existen hoy dentro del Estado español y en Hispanoamérica (Resina apud Cornejo \& Villamandos 20II: 13).

La verdad es que impresiona comprobar que lo que a muchos hispanistas les parece una amable afición y un pacífico quehacer (el hispanismo) puede desencadenar tanto encono y violencia a la hora de plantear y analizar una «crisis del hispanismo» y en la retórica que acompaña. De «Desolación y miseria del hispanismo » se ha hablado (Loureiro 1995), de «siete tesis contra el hispanismo» es autor Eduardo Subirats (2004) y se ha llegado a denunciar además del «sistema patriarcal, heteronormativo y logocéntrico» del español, un hispanismo incapaz de desarrollar un corpus teórico «en español propio y de prestigio» (Cornejo \& Villamandos 20II: 12) y hasta el «carácter trasnochado y obsoleto del concepto mismo ${ }^{15}$.

I3 Cfr., p. e., Nuevo hispanismo. Revista crítica de literatura y sociedad publicada por la Universidad Internacional Menéndez Pelayo a partir de 1982, de corta vida. Cfr. Álvarez León (20II) o Nuevos caminos del hispanismo (20I0), título de las Actas del XVI congreso de la AIH, celebrado en París, en 2007.

I4 Dicha «otredad» justifica la existencia de líneas de estudio e investigación específicas sobre sub- u otras áreas culturales como Cataluña, Galicia, Perú, etc. A un «nuevo hispanismo plural» se refiere Víctor Fuentes a propósito de Xoán González Millán (2007).

I5 Cfr. «outmoded idea based on essentialist, ideologically driven, and Spain-centric notions that will ultimaly do more to divide than to promote» (Shumway apud Cornejo \& Villamandos 20II: 13). 
Muchos de estos cuestionamientos tienen que ver, por supuesto, con el relativo desfase que casi siempre se puede observar entre la evolución del propio objeto de estudio y la evolución de la disciplina ya que como recordaba Américo Castro en I929 en un discurso leído en francés: «l'hispanisme a évolué avec la nature de l'objet qui lui fournissait son thème» (I929: 34) y no pocas consecuencias sobre las orientaciones del hispanismo ha tenido la creciente pregnancia de lo hispanoamericano vs la tradición española y "europea” y también la nueva organización del Estado español.

Con el paso del tiempo, el objeto de estudio se ha hecho cada vez más abierto, dinámico y procesal, y se han dignificado aspectos marginales y minorizados (formas literarias, culturas y lenguas). Al mismo tiempo, ha evolucionado la perspectiva desde la que se enfocan los objetos de estudio; en la lingüística hispánica tradicional, por ejemplo, el contacto entre lenguas se concebía como mero trasvase de formas, mientras que en los nuevos enfoques se han abierto las fronteras a otras disciplinas, como las ciencias sociales (Zimmermann 20Io). Todo esto ha derivado en la adopción de un nuevo paradigma de pluralismo e hibridez.

A propósito del estatuto de lo hispanoamericano dentro del hispanis$\mathrm{mo}^{16}$, conviene tener en cuenta las relaciones entre las antiguas colonias y la antigua potencia colonial -la «madre patria»- y todo el lastre de muchos años de afirmación/imposición de una hispanidad o de una percepción muy ideológica e imperialista del hispanismo concebido como

articulación de una sociedad transnacional sostenida en una identidad cultural, basada en el idioma, la religión, la historia y las costumbres o usos sociales; una comunidad imaginada que reunía España con el conjunto de las repúblicas americanas, otorgándole a la antigua metrópoli un puesto al menos de primogenitura cuando no de ascendente bajo la muy extendida expresión de Madre Patria (Sepúlveda Muñoz apud Vila Vilar 2012: 29).

Esta visión o concepción del hispanismo que remite a una situación histórica factualmente superada ${ }^{17}$, se ve que, además de unos pertinaces recelos, tiene por consecuencia la muy limitada incorporación de los hispano-americanos en el hispanismo, por su escasa conciencia de ser hispanistas y una tendencia a la autoexclusión, menos en Argentina y tal vez en México, cuando de estudios relacionados con la cultura hispánica clásica se trata.

Algo parecido puede observarse en las más o menos conflictivas relaciones entre algunas comunidades culturales de España y la cultura «es-

I6 Conste que existe un hispanoamericanismo que se reivindica como tal.

I7 Cfr., sin embargo, Caballé \& Pope (2014) donde parece privilegiarse el interés de los hispanistas norteamericanos por España. 
pañola», con una marcada tendencia a la diferenciación dentro del propio hispanismo y la fundación de asociaciones específicas de estudios catalanes, gallegos, etc.

Como consecuencia global de estas críticas más o menos convergentes, de «las ideologías que subyacen» (Cornejo \& Villamandos 20II: 19), se reivindica para el hispanismo un nuevo paradigma que dé cabida a la diversidad y heterogeneidad» (Cornejo \& Villamandos 20II: I) y también abandonar de hecho el acuñado concepto de hispanismo para adoptar una denominación más pragmática pero también de alcance mucho más limitado, como estudios hispánicos o, con la voluntad de incluir unas áreas no hispanófonas, ibéricos ${ }^{18}$, incluidas las lenguas y culturas de contacto y de migración.

Sin querer minimizar esa «crisis del hispanismo», tal vez convenga, no obstante, relacionarla con unas evoluciones más generales.

Observar, por ejemplo, que de contribuidores natos al acervo crítico y erudito, los hispanismos «de fuera» han pasado a ser meros colaboradores, al afirmarse España y la investigación española y la de muchos países hispanoamericanos dentro del concierto científico hispanista. De un hispanismo de sustitución se ha llegado a un hispanismo de cooperación (Botrel 2006), lo cual no quita que siga haciendo falta una perspectiva «desde fuera» como bien recuerda Morales Moya (apud Álvarez Barrientos 20II: 185).

Observar también que la «crisis del hispanismo» se ha de relacionar con la crisis de las humanidades y con los efectos de la globalización.

Para el hispanismo, la crisis general de las humanidades (de «debacle» hablan los más pesimistas -Talens 2003) se ve como acentuada por la pertinaz inferioridad y dependencia de la disciplina con respecto a las disciplinas dominantes en el establishment universitario (los estudios literarios e históricos, por ejemplo) o a las corrientes más o menos innovadoras que marcan la pauta intelectual como el tema del canon, del género, de lo marginal, pero también propios de tal o cual Estado o país (por el plurilingüismo o la pluriculturalidad como en la península ibérica o en Estados Unidos) y de tal o cual sistema académico (los cultural studies «dominantes» en la universidades norteamericanas, por ejemplo (véase Labany 2007).

También son de tener en cuenta los efectos de la globalización señalados por Gonzalo Navajas (2002: 6) y Jenaro Talens (2003) ${ }^{19}$, con la pérdida de identidad o su reconstrucción con relación al mundo anglosajón que acarrea la competencia que este le hace al hispanismo en muchos ámbitos,

I8 Cfr., por ejemplo, Del hispanismo a los estudios hispánicos (Resina 2009), los dos volúmenes dirigidos por Pérez Isasi (2013, 2017) o el International Journal of Iberian Studies.

I9 «Nos movemos en entramados de redes y no en compartimentos estancos», escribe Talens (2003). 
incluso lingüísticos ${ }^{20}$, causa de muchas dificultades y de una «pérdida de aura» (Pope 2003: 6).

No todas estas observaciones y críticas pueden aplicarse a todos los hispanismos, ni en muchos puntos al propio hispanismo "oficial": obsérvese que tienen mucho que ver con el hispanismo norteamericano y la "hispanización" de muchos hispanistas "de fuera", cada vez más oriundos de España e Hispanoamérica ${ }^{21}$, y no se puede esperar que la situación actual del hispanismo y la percepción de una eventual crisis sea uniforme; depende de las distintas tradiciones y expectativas de los distintos hispanismos: el hispanismo serbio, egipcio o guineoecuatoriano (Boleká 2018) no tendrán las mismas características o preocupaciones que el hispanismo estadounidense y un hispanismo emergente privilegiará la enseñanza de la lengua (no desconectada de un entorno cultural, económico, etc.), antes de que se constituya una línea de investigación parecida a las de los hispanismos asentados (Zdzislaw 2012) y, sin embargo, pertenecen al hispanismo, dialogan con los demás hispanismos ${ }^{22}$. Conste que para el hispanismo, la elaboración de un diccionario pragmático español-árabe o la publicación de estudios sobre los particularismos del español hablado en contextos plurilingües subsaharianos pueden tener tanta o más relevancia que una enésima edición del Quijote.

Tantas interrogaciones a propósito del hispanismo «actual», como ya decía Dámaso Alonso en 1965, del hispanismo «que viene» o de los «nouveaux chemins de l'hispanisme» ${ }^{23}$ ¿serán, como sugiere Pozuelo (2003) un «paso

20 «El inglés se ha constituido paradójicamente en el vehículo fundamental de los escritos críticos y teóricos del hispanismo contemporáneo, peninsular y latinonamericano y en la universidad norteamericana se privilegian las publicaciones en inglés en editoriales universitarias norteamericanas», observan Cornejo y Villamandos (20II: 19-20). Pero Culture E History Digital Journal es una revista del Instituto de Historia del Consejo Superior de Investigación Científica (CSIC) español y en su $\mathrm{n}^{\circ} 7$ dedicado a Cultural imaginaries in post-war and spanish exile of 1939 se recogen, por ejemplo, contribuciones en inglés de Francisco Javier Dosil, Consuelo Naranjo, Manuel Aznar, Dolores Fernández-Martínez, etc. El español es una de las pocas lenguas que mantiene su vigencia como lengua de publicación en contextos internacionales, aunque el inglés ha ido ganando terreno sobre todo entre los hispanistas más jóvenes. Según observa Johannes Kabatek (Diez aspectos...), sin embargo, los hispanistas elevarían más el prestigio del español en la comunicación científica participando más en foros anglófonos. Por su parte, Angel López García (2010: 193) subraya la inadecuación del español como lengua de la ciencia, junto con su avance como lengua vehicular complementaria en los negocios.

2I Llama la atención el que la mayor parte de los colaboradores en el volumen dirigido por Cornejo \& Villamandos (20II) sea universitarios estadounidenses de origen español o hispanoamericano. Otra sensación se desprende del libro de García Cárcel y Serrano Martín dedicado a los hispanistas franceses de raíz española (2009).

22 Véase, por ejemplo, el proyecto cultural y de investigación Casa de África, fundado en 1997, y la celebración, en 2017, de las II Jornadas de Literaturas Hispanoafroamericanas. Del Mediterráneo al Pacífico (cfr. http://casa-de-africa.blogspot.com/p/inicio.html).

23 Título del seminario anunciado por la Casa de Velázquez (I6-I7.IO.2018) donde el hispa- 
más en la dialéctica de la evolución de la disciplina»? Lo cierto es que el hispanismo no peca por excesos de debates sobre su esencia y entre las vehementes tesis de Subirats se puede encontrar una recomendación muy sensata: «el nuevo hispanismo debería examinar sus propias limitaciones conceptuales y sus desfallecientes proyectos para revisar reflexivamente su pasado y abrir una alternativa original para el futuro» (2004: 163).

$\mathrm{Al}$ hispanismo le conviene no quedarse varado y como ensimismado ${ }^{24} \mathrm{en}$ una «cómoda y halagüeña insularidad», seguir evolucionando, adaptándose si cabe a unas nuevas condiciones y situaciones, y desenmismarse para todos los efectos (Botrel 2007).

En un momento en el que el hispanismo por muy "en crisis" que esté, goza de una envidiable salud y muestra una vitalidad que no se puede ignorar, conviene tomar conciencia de los límites de un hispanismo estricta o mayoritariamente filológico y clásico y ampliar la relación del hispanismo con otras disciplinas académicas, pero también, tal vez, "salir del estrecho círculo académico", tomando en cuenta la utilidad social y económica del hispanismo y los avances tecnológicos, sin renunciar, por supuesto, a su crítica; tener conciencia del peligro de una desconexión entre la tradición universitaria y las expectativas de la sociedad ${ }^{25} \mathrm{y}$ abogar por un hispanismo «comprometido con su momento histórico y su función crítica» (Cornejo \& Villamandos 20II: I6), por una disciplina «abierta y dinámica, basada en un diálogo interdisciplinar, textual y teórico, y con unas fronteras cada vez más porosas y precarias» desde una posición necesariamente «híbrida y dialógica».

Con esta saludable reflexión sobre lo que es el hispanismo, la pretensión no es establecer un nuevo paradigma que resultaría de un hipotético "descentramiento" con respecto a otro paradigma «centrado en la cultura elevada y una idea nacional preestablecida, un canon rígido y una teoría inflexible» (Cornejo \& Villamandos 20II: 15), pero sí abogar por un hispanismo no hegemónico ni unívoco, sino abierto, plural y al mismo tiempo crítico y combativo; podría decirse: emprendedor.

Y sobre todo fomentar y fortalecer la conciencia de lo que es ser hispanista; de lo que es obrar como hispanista, al margen de las categorías académicas, habida cuenta de que, si aceptamos el reto de la interdisciplinariedad, la identidad de un estudioso no tiene por qué ser monolítica, sino más bien flexible y abarcadora.

nista queda definido como «tout chercheur travaillant sur des thématiques liées à l'Espagne et à l'Amérique latine comme espaces linguistiques, comme entités géographiques, comme constructions historiques et culturelles».

24 Cfr. Luisa Elena Delgado (2004: 7). Un hispanismo «absorto y solipsista», según Cornejo \& Villamandos 2011 .

25 «ajeno a la sociedad contemporánea de la que dice hacerse eco» (Cornejo \& Villamandos 20II). 


\section{Bibliografía}

Altamira, Rafael, «Hispanólogos e hispanófilos», en De historia y arte, Madrid, Librería de Victoriano Suárez, I898.

Álvarez Barrientos, Joaquín (ed.), Memoria de hispanismo, Miradas sobre la cultura española, Madrid, Siglo XXI, 201 .

Alvárez León, Luis, Nuevas perspectivas en el hispanismo, San Sebastián de los Reyes (Venezuela), Fondo Editorial La Pitahaya, 2011.

Bernardete, Mair José, Hispanismo de los sefardíes levantinos, Madrid, Aguilar, 1963.

Bolekia Boleká, Justo, «Impresiones y conmociones culturales en el afrohispanismo africano», en Trans-afrohispanismos. Puentes culturales críticos entre África, Latinoamérica y España, Foro Hispánico, Volumen 58, Madrid, Brill / Rodopi, 2018.

Boletín de la Asociación Internacional de Hispanistas, Io/03, 2004.

Boletín de la Fundación Federico García Lorca, 33-34, 2003.

Botrel, Jean-François, «El hispanismo hoy y su trascendencia internacional», en Enciclopedia del Español en el Mundo. Anuario del Instituto Cervantes 2006-2007, Madrid, Instituto Cervantes, 2006, pp. 445-448.

-. «Alocución [...] en el acto inaugural del XVI Congreso de la Asociación Internacional de Hispanistas (París, 9 de julio de 2007), en Actas del XVI Congreso de la Asociación Internacional de Hispanistas. París, julio de 2007. Nuevos caminos del hispanismo..., eds. Pierre Civil \& Françoise Crémoux, Madrid /Fráncfort del Meno, Iberoamericana / Vervuert, 2010, pp. 49-52.

-. «Ser hispanista», en El español en el mundo. Anuario del Instituto Cervantes 20I4, Madrid, Instituto Cervantes y AEBOE, 20I4, pp. 95-II4.

—. «La Europa de los hispanistas», Cuadernos AISPI. Estudios de lenguas y literaturas hispánicas, I3-I, 2019, pp. I45-I72.

Caballé Masforroll, Anna \& Pope, Randolph D. (eds.), ¿Por qué España? Memoria del hispanismo estadounidense, Barcelona, Galaxia Gutenberg, 2015.

Castro, Américo, «Discours», en Inauguration de l'hôtel de l'Institut d'Études Hispaniques de l'université de Paris 29 mai 1929, Paris, Institut d'Études Hispaniques, 1929, pp. 32-37.

Cornejo, Rosalía \& Villamandos, Alberto (eds.), Un hispanismo para el siglo XXI. Ensayos de crítica cultural, Madrid, Biblioteca Nueva, $201 \mathrm{I}$.

Delgado, Luisa Elena, «El hispanismo ensimismado», Lateral: revista de cultura, 109, 2004, p. 7 .

Durán, Rosa, «La sacralización de los maestros», Lateral: revista de cultura, I05, 2003, pp. 6-7.

Egido, Aurora \& Schwartz, Lia (coord.), Las humanidades y el hispanismo, Ínsula, 725, 2007.

Epps, Brad, «Hispanismo, generalísimo», Lateral: revista de cultura, IOI, 2003, p. 6. 
Epps, Brad \& Fernández Cifuentes, Luis (eds.), Spain Beyond Spain: Modernity, Literary History and National Identity, Lewisburg, Bucknell UP, 2005.

Eyeang, Eugénie, L'enseignement-apprentissage de l'espagnol au Gabon. Eléments de recherche pour une adaptation socio-didactique, Université de Grenoble, 1997, [Thèse de doctorat], Villeneuve-d'Ascq, ANRT, I999.

Fuentes, Víctor, «Xoán González-Millán y el nuevo hispanismo plural», Actas VII Congreso Internacional de Estudos Galegos. Mulleres en Galicia: Galicia e os otros pobos da península, coord. Helena González Fernández \& María Xesús Lama López, [Galicia], Ediciós do Castro, 2008, pp. 73-74.

García Cárcel, Ricardo \& Serrano Martín, Eliseo (eds.), Exilio, memoria personal y memoria histórica. El hispanismo francés de raíz española en el siglo $X X$, Zaragoza, Institución Fernando el Católico, 2009.

Gullón, Germán, «Entre la espada y la pared. Hispanismo a debate (2)», Lateral: revista de cultura, 96, 2002, p. 6.

Guittard, Jean-Michel, Répertoire des thèses française relatives au monde ibérique et ibéro-américain des origines à 1980, [Burdeos]/ [París], Maison des Pays Ibériques / Klincsieck, 1993.

Kabatek, Johannes, «Diez aspectos del presente y futuro del hispanismo», Disponible en línea en Academia.edu: http://www.academia.edu/II887832/_ Diez_aspectos_del_presente_y_futuro_de_la_hispanística_.

Labanyi, Jo, «¿Estudios culturales o historia cultural?», Insula, 725, 2007, pp. I5-18.

Lateral. Revista de cultura, 2002-2004.

López García, Ángel, El boom de la lengua española. Análisis ideológico de un proceso expansivo, Madrid, Biblioteca Nueva, 2007.

—. «¿Norma endógena o exógena para la lengua española?», Glosas, 8, 2015, pp. 2I-38.

López Suaces, Marta, «¿Qué queremos decir cuando decimos hispanismo?», Lateral: revista de cultura, I08, 2003, p. 6.

Loureiro, Ángel G., «Desolación y miseria del hispanismo», Quimera, I39, I995, pp. 3I-36.

Macciuci, Raquel, «Hispanismo y crítica hispánica al Sur. Sobre periferias, centros y des-centramientos», Orbis Tertius, I2, 2006. Disponible en línea.

Mainer, José-Carlos, «Clavileño (1950-1957): cultura de Estado bajo el franquismo», Bulletin Hispanique, 104/2, 2002, pp. 94I-963.

Moraña, Mabel (ed.), Ideologies of Hispanism, Nashville, Tennessee, Vanderbilt UP, 2005.

Navajas, Gonzalo, «El hispanismo en la era global», Lateral: revista de cultura, 95, 2002, p. 6.

Nuevo hispanismo. Revista crítica de literatura y sociedad, 1982. 
Nuevos caminos del hispanismo, Actas del XVI congreso de la AIH, eds. Pierre Civil \& Françoise Crémoux, Madrid /Fráncfort del Meno, Iberoamericana / Vervuert, 2 oio.

Ortega, Julio (ed.), Nuevos hispanismos interdisciplinarios y transatlánticos, Madrid / Fráncfort del Meno, Iberoamericana / Vervuert, 20 Io.

Ortega, Julio (ed.), Nuevos hispanismos: para una crítica del lenguaje dominante, Madrid / Fráncfort del Meno, Iberoamericana / Vervuert, 2012.

Pascual, José Antonio, «Un hispanismo desensimismado», Hispanisme/S, 6, 20I5, pp. II-I6.

Pérez Isasi, Santiago \& Fernandes, Angela (eds.), Looking at Iberia: a comparative European perspective, Berna, Peter Lang, 2013.

Pérez Isasi, Santiago (dir.), Los límites del hispanismo: nuevos métodos, nuevas fronteras, nuevos enfoques, Berna, Peter Lang, 2017.

Pope Randolph, «El hispanismo dionisiaco», Lateral: revista de cultura, Io6, 2003, p. 6.

Pozuelo Yvancos, «Hispanismo y retórica de la crisis», Lateral: revista de cultura, 99, 2003 , p. 6.

Quimera. Revista de literatura, «Dossier sobre el hispanismo», I39, I995.

Resina, Joan Ramón, Del hispanismo a los estudios ibéricos. Una propuesta federativa para el ámbito cultural, Madrid, Biblioteca Nueva, 2009.

Riesgo Martín, Begoña, Christian Lagarde, Philippe Meunier (eds.), Hispanismo europeo, Hispanisme/S, 6, 20I5. Disponible en línea.

Sampedro, Benita \& Doubleday, Simon (eds.), Border Interrogations: Questionning Spanish Frontiers, Nueva York, Berghahn Books, 2008.

Sánchez Albornoz, Nicolás, «Apunte sobre el hispanismo», en El hispanismo anglonorteamericano : aportaciones, problemas y perspectivas sobre historia, arte y literatura españolas (siglos XVI-XVIII): Actas de la I Conferencia Internacional "Hacia un Nuevo Humanismo», ed. José Manuel Bernardo Ares, C.I.N.H.U., Córdoba, 9-I4 de septiembre de I997, Córdoba, I997, pp. I77-I80.

Subirá, José, El hispanismo y el italianismo musicales en la época de la tonadilla, s. n., I924.

Subirats, Eduardo, «Siete tesis contra el hispanismo», Revista de Humanidades. Tecnológico de Monterrey, I7, 2004, pp. I49-I66.

Talens, Jenaro, «Hispanismo y globalización», Lateral: revista de cultura, 97, 2003, p. 6.

Tietz, Manfred, «Desde el "hispanismo alemán” a la Asociación Alemana de Hispanistas: la prehistoria y la fundación de la Asociación», en La Asociación Alemana de Hispanistas (I977-20I7), ed. Óscar Loureda, Madrid / Fráncfort del Meno, Iberoamericana / Vervuert 20I7, pp. 29-55.

Valle, José del, «Panhispanismo e hispanofonía: breve historia de dos ideologías siamesas», Sociolinguistic Studies, 5, 3, 2012, pp. 465-484. 
Valle, José del \& Gabriel-Stheeman, Luis (eds.), La batalla del idioma. La intelectualidad hispánica ante la lengua, Madrid / Fráncfort del Meno, Iberoamericana / Vervuert, 2004.

Vila Vilar, Enriqueta, Hispanismo e hispanización: el Atlántico como nuevo Marenostrum, Madrid, Real Academia de la Historia, 2012.

Zdzislaw, Wasik (comp.), Del español al hispanismo: docencia e investigación, Wroclaw, Philologica Wratilaviensia: Studia Iberica et Latinoamericana, 2012.

Zimmermann, Klaus, «La hispanofonía, la lingüística hispánica y las Academias de la Lengua: propuestas para una nueva cultura lingüística», en Nuevos hispanismos interdisciplinarios y transatlánticos, ed. Julio Ortega, Madrid / Fráncfort del Meno, Iberoamericana / Vervuert, 20I0, pp. 43-59. Zugasti, Miguel (ed.), Estudios de hispanismo contemporáneo. Actas del primer seminario internacional sobre Hispanismo en el siglo XX, New Delhi, Embajada de España, 1990. 